\title{
Nonpathologic Infection of Macaques by an Attenuated Mycobacterial Vaccine Is Not Reactivated in the Setting of HIV Co-Infection
}

Taylor W. Foreman, ${ }^{* \dagger}$ Ashley V. Veatch, ${ }^{*}$ Denae N. LoBato, ${ }^{*}$ Peter J. Didier, ${ }^{*}$ Lara A. Doyle-Meyers, ${ }^{*}$ Kasi E. Russell-Lodrigue, Andrew A. Lackner, ${ }^{* \dagger}$ Konstantin G. Kousoulas, ${ }^{\ddagger \S}$ Shabaana A. Khader, ${ }^{\mp}$ Deepak Kaushal, ${ }^{\star \dagger}$ and Smriti Mehra ${ }^{* \$ \delta}$

From the Tulane National Primate Research Center, ${ }^{*}$ Covington, Louisiana; the Department of Microbiology and Immunology, ${ }^{\dagger}$ Tulane University School of Medicine, New Orleans, Louisiana; the Center for Biomedical Research Excellence ${ }^{\ddagger}$ and the Department of Pathobiological Sciences, ${ }^{\S}$ Louisiana State University School of Veterinary Medicine, Baton Rouge, Louisiana; and the Department of Molecular Microbiology, "Washington University School of Medicine, St. Louis, Missouri

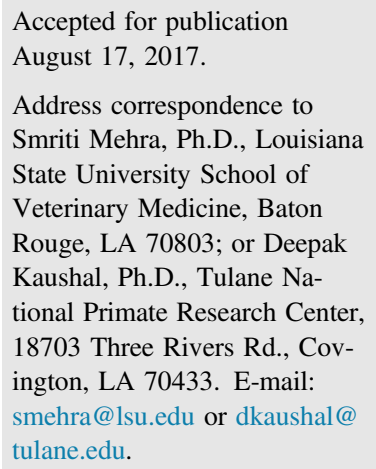

\begin{abstract}
Failure to replace Bacille Calmette-Guerin vaccines with efficacious anti-tuberculosis (TB) vaccines have prompted outside-the-box thinking, including pulmonary vaccination to elicit local immunity. Inhalational $M t b \Delta s i g H$, a stress-response-attenuated strain, protected against lethal TB in macaques. While live mycobacterial vaccines show promising efficacy, HIV co-infection and the resulting immunodeficiency prompts safety concerns about their use. We assessed the persistence and safety of Mtb $\Delta$ sigH, delivered directly to the lungs, in the setting of HIV co-infection. Macaques were aerosol-vaccinated with $\Delta$ sigH and subsequently challenged with SIVmac 239 . Bronchoalveolar lavage and tissues were sampled for mycobacterial persistence, pathology, and immune correlates. Only $35 \%$ and $3.5 \%$ of lung samples were positive for live bacilli and granulomas, respectively. Our results therefore suggest that the nonpathologic infection of macaque lungs by $\Delta s i g H$ was not reactivated by simian immunodeficiency virus, despite high viral levels and massive ablation of pulmonary $\mathrm{CD}^{+}{ }^{+} \mathrm{T}$ cells. Protective pulmonary responses were retained, including vaccine-induced bronchus-associated lymphoid tissue and $\mathrm{CD}^{+}$effector memory $\mathrm{T}$ cells. Despite acute simian immunodeficiency virus infection, all animals remained asymptomatic of pulmonary TB. These findings highlight the efficacy of mucosal vaccination via this attenuated strain and will guide its further development to potentially combat TB in HIV-endemic areas. Our results also suggest that a lack of pulmonary pathology is a key correlate of the safety of live mycobacterial vaccines. (Am J Pathol 2017, 187: 2811-2820; https://doi.org/10.1016/j.ajpath.2017.08.014)
\end{abstract}

Mucosal vaccination is being considered as a viable alternative to the systemic route, ${ }^{1}$ especially for lung pathogens like Mycobacterium tuberculosis $(M t b)$. Patients who undergo pulmonary mucosal vaccination can benefit from the unique physiology and the immune system in the lung. The respiratory system serves as the route of entry for numerous pathogens, which the lungs have evolved to contain by invoking rapid innate responses. Large surface area provides the lungs with greater probability for interaction with the pathogen. Moreover, the mucosa in the airways and the parenchyma contain dendritic cells, which can phagocytose $M t b$ for efficient elicitation of adaptive responses via class I and II presentation. ${ }^{2}$ Antibodies are known to passively transfer through the lung epithelium into the alveoli. Furthermore, pulmonary immune cells can elicit the formation of local bronchus-associated lymphoid tissue (BALT), the presence of which is strongly correlated with natural ${ }^{3,4}$ or

This research was supported by NIH awards R21AI127160, R21AI127222, and P30GM110760 (S.M.); R01AI089323 (D.K.); and R01AI111914 (S.A.K./D.K.); and Tulane National Primate Research Center grants P51OD011104 and C06AI058609.

This article is dedicated to the memory of Dr. Andrew A. Lackner, DVM, PhD, DACVP, long-serving director of the Tulane National Primate Research Center, who passed away after the submission of the initial version of the manuscript.

Disclosures: None declared. 
vaccine-induced ${ }^{5}$ immunity to tuberculosis (TB), as well as to HIV-induced reactivation of latent tuberculosis infection ${ }^{6}$ in the human-like macaque model. ${ }^{7,8}$ Mucosal vaccination against pulmonary infectious agents can result in the elicitation of local, antigen-specific, as well as broad-spectrum Band T-cell responses, at the very site of the infection, resulting in more efficient protection.

Live attenuated mycobacterial vaccines demonstrate promising efficacy in protecting against TB. ${ }^{9}$ Due to the presence of a virtually complete array of antigens, such vaccines elicit a breadth of immune responses not obtained by vector or proteinsubunit strategies, increasing the likelihood of protection. ${ }^{10}$ Live vaccines can mimic natural infection through persistent antigenic stimulation, promoting stronger, long-lived immunity. However, a balance must exist between the pathogenicity and attenuation of the strain. Deletion various virulence pathways in $M t b$ is likely to result in a reduction of infectivity, and arguably some of these mutations may generate the preferred combination of persistence, immunogenicity, and nonpathogenicity. ${ }^{11-14}$ HIV remains endemic to the regions of high TB prevalence. Bacille Calmette-Guerin (BCG), a live attenuated Mycobacterium that is one of the most widely used vaccines in the world, is efficacious against severe forms of TB. However, BCG is contraindicated in individuals with impaired immunity, including pregnant mothers and HIV-infected individuals. ${ }^{15}$ The realization of a TB-free world is therefore contingent upon finding safe, novel, and efficacious replacements for BCG. ${ }^{16}$

The World Health Organization recommends immunization with BCG as soon as possible after birth in infants born in endemic areas. Infants with symptomatic HIV disease are not immunized with BCG due to significantly increased rates of BCG-induced disease and the unknown efficacy of vaccinating HIV-infected infants ${ }^{17-19}$; however, it is recommended that infants in whom AIDS has not developed or who might subsequently become HIV infected still be vaccinated. The risk for acquiring vaccine-induced disease poses a significant problem for the implementation of novel live attenuated mycobacterial vaccines; therefore, each vaccine candidate must be tested for persistence and safety upon subsequent HIV infection. There is currently only one new live attenuated mycobacterial vaccine in clinical trials, ${ }^{20}$ while there are multiple preclinical vaccines that have shown moderate to strong protection and varying immunogenicity. The $M t b \Delta s i g H$ mutant induced a nonpathogenic infection in macaques $^{21}$ and pulmonary vaccination, with this strain protected significantly against subsequent lethal challenge with homologous $M t b .{ }^{5}$ We previously demonstrated that this protection was strongly associated with the recruitment of central memory $\mathrm{T}\left(\mathrm{T}_{\mathrm{CM}}\right)$ cells to the lung and with the presence of vaccineinduced BALT. ${ }^{5}$ While these results were highly promising for clinical implementation of this live attenuated mycobacterial vaccine, safety concerns were noted due to the vaccine strain containing only a single gene deletion and possible persistence of the bacteria in the vaccinated individual.

In the current study, we aerosol-vaccinated five macaques with $\Delta \operatorname{sig} H$ and subsequently infected each macaque with simian immunodeficiency virus (SIV). We hypothesized that if $\Delta \operatorname{sig} H$ was not adequately attenuated, some of the macaques could potentially develop signs of TB disease, including dissemination of bacilli and uncontrolled bacterial replication in the lung, as have been replicated for BCG in this model. ${ }^{22}$

\section{Materials and Methods}

\section{Macaques}

Five mycobacteria-naive adult Indian rhesus macaques, bred and housed at the Tulane National Primate Research Center (TNPRC) and ranging from approximately 3 to 9 years in age and 4.0 to $11.6 \mathrm{~kg}$ in weight, were aerosol-vaccinated, as described earlier (for $M t b$ ), ${ }^{5,6,21,23-29}$ to a high-dose [approximately 1000 colony-forming units (CFU) implanted] of $\Delta s i g H$ isogenic deletion mutant in the Mtb CDC1551 background. $^{5,21,30,31}$ All macaques were exposed 9 weeks after vaccination to $300 \mathrm{TCID}_{50}$ of $\mathrm{SIVmac}_{239}$ administered intravenously in $1 \mathrm{~mL}$ saline, as described earlier. ${ }^{6,24}$ All animal procedures were approved by the TNPRC Institutional Animal Care and Use Committee and performed in strict accordance with NIH guidelines. ${ }^{32}$ The TNPRC is accredited by the Association of Assessment and Accreditation of Laboratory Animal Care as well as by the US Department of Agriculture. Criteria for euthanasia included presentation of four or more of the following conditions: i) body temperatures consistently $>2{ }^{\circ} \mathrm{C}$ above preinfection values for 3 or more weeks in a row; ii) $15 \%$ or more loss in body weight; iii) serum C-reactive protein (CRP) values higher than $10 \mathrm{mg} / \mathrm{mL}$ for 3 or more consecutive weeks (CRP is a marker for systemic inflammation that exhibits a high degree of correlation with active TB in macaques ${ }^{8,24}$ ); iv) chest radiography TB pathology values higher than 2 on a scale of 0 to 4 ; v) dyspnea; vi) significant or complete loss of appetite; and vii) detectable bacilli in bronchoalveolar lavage (BAL) samples.

\section{Nonhuman Primate Sample Collection and Clinical Procedures}

Samples were collected before and after vaccination, as well as after SIV infection. Chest radiographs were acquired before and 3 weeks after vaccination and 1 and 7 weeks after SIV infection, as previously described. ${ }^{5,6,24,25,27,33,34}$ The chest radiographs were scored by veterinary clinicians (L.A.D.-M. and K.E.R.-L.) in a blinded fashion on a subjective scale of 0 to 4 , with a score of 0 denoting normal lung and a score of 4 denoting severe tuberculous pneumonia, as previously described. ${ }^{5}$ Before vaccination, all five animals received a normal score of 0 . Blood was drawn before vaccination and then weekly thereafter for measuring complete blood count and serum chemistry. ${ }^{24,25}$ Blood collected in EDTA tubes (Sarstedt AG \& Co., Nümbrecht, Germany) was used for whole blood flow cytometry using the panels as described earlier. ${ }^{5,25,27}$ BAL samples were obtained, as previously described, before vaccination and again at $3,7,11$, and 14 weeks ${ }^{24,25}$ and then analyzed for CFU values and flow cytometry. 
Table 1 Vaccinated Animals

\begin{tabular}{|c|c|c|c|c|}
\hline Animal & Age, y & Sex & $\begin{array}{l}\text { Weight } \\
\text { prevaccination, } \mathrm{kg}\end{array}$ & $\begin{array}{l}\text { Tuberculin } \\
\text { skin test } \\
\text { prevaccination }\end{array}$ \\
\hline KH76 & 2.8 & Male & 4.0 & - \\
\hline KF62 & 2.9 & Male & 4.1 & - \\
\hline GB13 & 9.5 & Female & 8.4 & - \\
\hline IM63 & 5.4 & Male & 11.0 & - \\
\hline JG35 & 4.4 & Male & 11.6 & - \\
\hline Means \pm SD & $5.0 \pm 2.7$ & NA & $7.8 \pm 3.6$ & NA \\
\hline
\end{tabular}

-, negative test result; NA, not applicable.

\section{Bacterial Burden and Pulmonary Pathology}

Humane end points were predefined in the animal use protocol and applied as a measure of reduction of discomfort. ${ }^{5}$ At necropsy, lung, spleen, and liver tissues were collected and processed, as previously described, using two sections of pulmonary tissue representing every lung lobe with at least one sample $^{5}$; CFU values were determined per gram of tissue. 3,5,6,21,24,25,27,33,34 Lung pathology at necropsy was determined as described earlier. ${ }^{6,25}$ TB pathology was determined for multiple sections in each lung and averaged for each animal in the study. SIV-induced pathology was reported per section, with multiple sections analyzed per animal. ${ }^{6}$

\section{Flow Cytometry}

Flow cytometry was performed on whole blood, BAL, lung, and bronchial lymph node samples from all animals, as previously described. 5,6,25,27 Briefly, cells were stained for 25 minutes on ice with antibodies CD3 (SP34-2), CD4 (L200), CD8 (RPA-T8), CD28 (CD28.2), and CD95 (DX2) (all from BD Biosciences, San Jose, CA) and washed twice with phosphatebuffered saline containing $2 \%$ bovine serum albumin and $0.45 \%$ sodium azide then permeabilized with the BD Fix/Perm Kit and stained with Ki67 (B56) (both from BD Biosciences) for 60 minutes on ice. Samples were fixed and acquired using a BD LSRFortessa cell analyzer. Data were analyzed using FlowJo software version 10.3 (Tree Star, Inc., Ashland, OR).

\section{Immunohistochemistry Analysis}

Fluorescent immunohistochemistry analysis, chromogenic staining, and in situ hybridization were performed on formalinfixed, paraffin-embedded tissue as previously described. ${ }^{6,35}$ Briefly, antigen retrieval was performed on tissue slides and stained with antibodies CD20 (L26), CD3 (polyclonal), and CD68 (KP1) (all, Dako/Agilent Technologies, Glostrup, Denmark) or CD163 (EDHu-1) (AbD Serotec, Kidlington, UK).

\section{Statistical Analysis}

All statistical comparisons were performed using a one-way analysis of variance, $t$-test, or Pearson correlation analysis in Prism software version 7.0b (GraphPad Software, Inc.,
La Jolla, CA) as described earlier. ${ }^{5}$ All data are presented as means \pm SEM.

\section{Results}

\section{Clinical/Pulmonary Correlates of Mycobacterial Infection in $\Delta s i g H$ Vaccination and SIV Infection}

Direct aerosolization of $\Delta s i g H$ into the lungs of macaques induced robust responses and impressive protection against lethal TB. Five macaques (Table 1) were therefore aerosolvaccinated with $1000 \mathrm{CFU}$ of $\Delta \operatorname{sig} H$ to test the safety of this strain in the setting of HIV co-infection. This dose has been shown to produce a nonpathogenic infection in macaques and to induce superlative protection upon subsequent lethal challenge when used as a vaccine. The vaccinated animals were allowed to rest for 9 weeks before high-dose i.v. challenge with SIV. This dose and route of SIV challenge are commonly used in HIV research to study pathogenic infection in rhesus macaques. In our experiment, this dose/route combination modeled acute HIV infection resulting in the rapid ablation of $\mathrm{CD} 4^{+} \mathrm{T}$ cells and overall dysfunction of immune responses to $M t b .{ }^{6}$ For comparison purposes, rhesus macaques latently infected with a low dose (10 $\left.10^{1} \mathrm{CFU}\right)$ of $\mathrm{Mtb}$ CDC1551 and subsequently infected with the same dose/route of SIV at the same time (9 weeks after aerosol infection with $M t b$ ) have been included in graphs (Figures 1 and 2) to demonstrate SIV-induced reactivation of TB disease (co-infected group). The lower dose of $M t b$ in these reactivated animals was chosen since $10^{3} \mathrm{CFU}$ of wild-type $M t b$ would lead to rapid death within 9 weeks. However, the low dose establishes latent infection in these animals and allows the study of reactivation by immunosuppression or SIV coinfection.

Immediately after vaccination, all animals maintained or gained weight (Figure 1A) and maintained temperature (Figure 1B), as shown as percent change compared to preinfection (baseline) weight and temperature. One in five animals exhibited elevated CRP 1 week after vaccination, which subsided by week 3 , while the other four vaccinated animals showed no increase in CRP for the entire study (Figure 1C). None of the animals had lung pathology as assessed by chest radiography 3 weeks after vaccination. Upon subsequent i.v. challenge with a high dose of pathogenic SIV, all vaccinated animals remained devoid of TB disease as evidenced by lack of weight loss, minimal change in temperature, and no increase in CRP (Figure 1, A-C). Conversely, co-infected animals demonstrate reactivation disease as evidenced by progressive weight loss, extensive pyrexia, and significantly elevated CRP levels (Figure 1). Thoracic radiographs of these animals further validated the lack of pulmonary disease in vaccinated animals (Supplemental Figure S1).

\section{Lung Bacterial Burden after SIV Infection}

We next investigated whether $\Delta$ sigH persists in the lungs of vaccinated macaques and whether infection with SIV would 


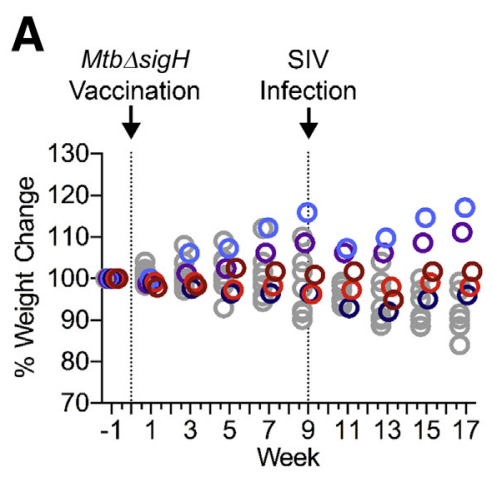

D

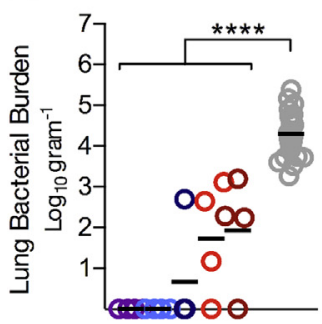

E
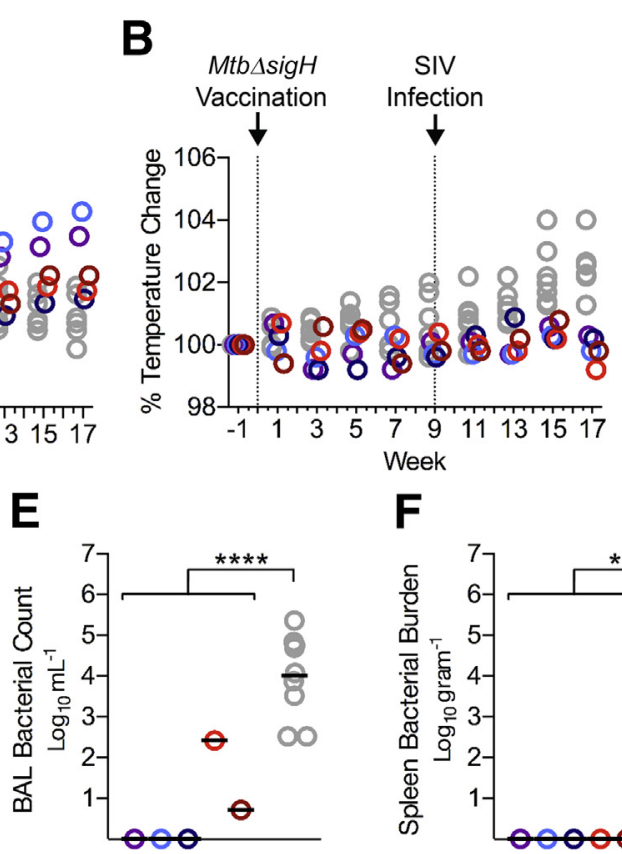

$\mathbf{F}$
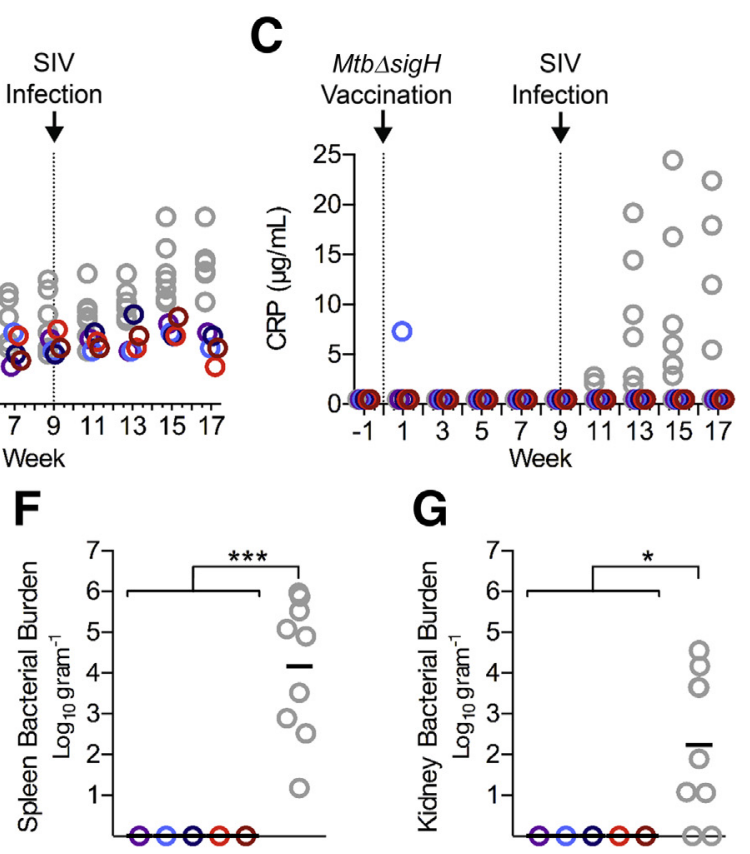

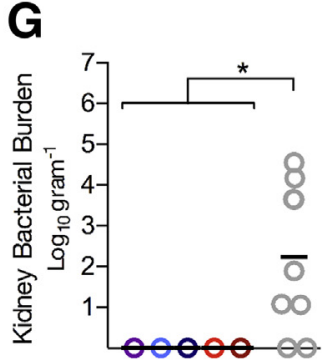

Figure 1 Clinical and bacteriologic correlates of $M t b \Delta s i g H$ vaccination and subsequent simian immunodeficiency virus (SIV) infection. Five Indian rhesus macaques were vaccinated with $1000 \mathrm{CFU}$ of $\mathrm{Mtb} \Delta \mathrm{sigH}$ and challenged with a high dose of $\mathrm{SIVmaC}_{239}$ at 9 weeks after vaccination. A-C: Comparisons of percent weight loss (A), percentage of temperature increases (B), and C-reactive protein (C) in Mtb $\Delta$ sigH-vaccinated animals (color) versus Mtb/SIV coinfected animals (gray). Dotted lines indicate day of vaccination or SIV challenge. D: Mtb $\Delta$ sigH bacilli present in the lung (in number per gram of tissue) at the time of euthanasia, with multiple lung sections sampled per animal. E-G: Vaccine bacilli present in bronchoalveolar lavage $(\mathbf{E})$, spleen $(\mathbf{F})$, and kidney (G). Data are expressed as means. ${ }^{*} P<0.05,{ }^{* * *} P<0.001$, and ${ }^{* * * *} P<0.0001$ using a $t$-test analyzing the mean values of all vaccinated animals versus Mtb/SIV-co-infected animals. CRP, C-reactive protein.

permit uncontrolled bacterial replication. Nine weeks after SIV challenge, the animals were humanely euthanized and tissues were extensively assessed for bacterial burden. From the 5 vaccinated animals, 13 of 20 lung sections tested were devoid of any detectable bacteria. Very low levels of $\mathrm{Mtb} \Delta \mathrm{sigH}$ could be cultured from the lungs of vaccinated animals $\left(10^{0.86}\right.$; mean, 7 bacilli/g of lung tissue) as compared to co-infected animals that had a significantly higher bacterial burden $\left(10^{4.3}\right.$; approximately 20,000 bacilli) (Figure 1D). To exclude potential skewing due to sterile lobes, the mean bacterial burden of vaccinated animals with only culturable bacteria was $10^{2.47}$ or approximately 300 CFU. However, animals that are able to maintain control of infection in a latent state have been found to have upward of $10^{3.5} \mathrm{CFU}$. Furthermore, a mean of 4 bacilli $\left(10^{0.62}\right)$ per milliliter of lavage fluid was recovered in BAL, while three animals had no detectable bacilli (Figure 1E). In comparison, a mean of 10,000 bacilli $\left(10^{4.0}\right)$ was recovered from $\mathrm{Mtb} / \mathrm{SIV}$ co-infected animals. ${ }^{6}$ These results are even more contrasting, since vaccinated animals received approximately 2-log $\left(10^{3}\right)$ more $M t b \Delta s i g H$ bacilli than was used in Mtb/SIV co-infection $\left(10^{1}\right)$ with wild-type $M t b$. Co-infection with $M t b$ and HIV in humans and macaques is characterized by extensive dissemination to extrathoracic organs. However, $\Delta s i g H$-vaccinated animals had no detectable bacilli in spleen or kidney (Figure 1, F and G). These results demonstrate that while vaccination with $\Delta s i g H$ is largely sterilized, very few bacilli persist and acute infection with SIV does not generate a permissive environment for excessive bacterial replication.

\section{Lung Pathology}

As shown before, pathology induced by aerosol vaccination with $\Delta s i g H$ remained insignificant as determined by both gross and histopathologic examination. Despite infection with SIV, $\Delta s i g H$-vaccinated macaques maintained minimal pathology (Supplemental Figure S2). Of 85 lung sections histopathologically examined, only 3 sections (3.5\%) revealed evidence of granulomatous inflammation (Figure 2, A-E). Each of these few granulomas were well-organized and lacked significant neutrophilic infiltrates. The severity of pulmonary pathology is increased in co-infected macaques versus only $M t b$-infected animals, making macaques a good model of the synergy between HIV and TB during co-infection. In vaccinated animals, however, interstitial pulmonary pathology parameters-including vasculitis/lymphangitis (Figure 2, F and G), septal thickening, type II pneumocyte hyperplasia, accumulation of foamy alveolar macrophages, and lymphohistiocytic perivasculitis-were significantly reduced compared to those in co-infected animals (Supplemental Figure S2), suggesting that SIV-induced pathology was not exacerbated in vaccinated animals.

Since diminished SIV replication could explain the lack of severe SIV-induced pathology and subsequent effects on the control of bacterial replication, we next assessed peripheral viral loads in plasma. While there were no distinct differences in peripheral viral loads during the entire study (Figure $2 \mathrm{H}$ ), differences in replication at the site of vaccination could 


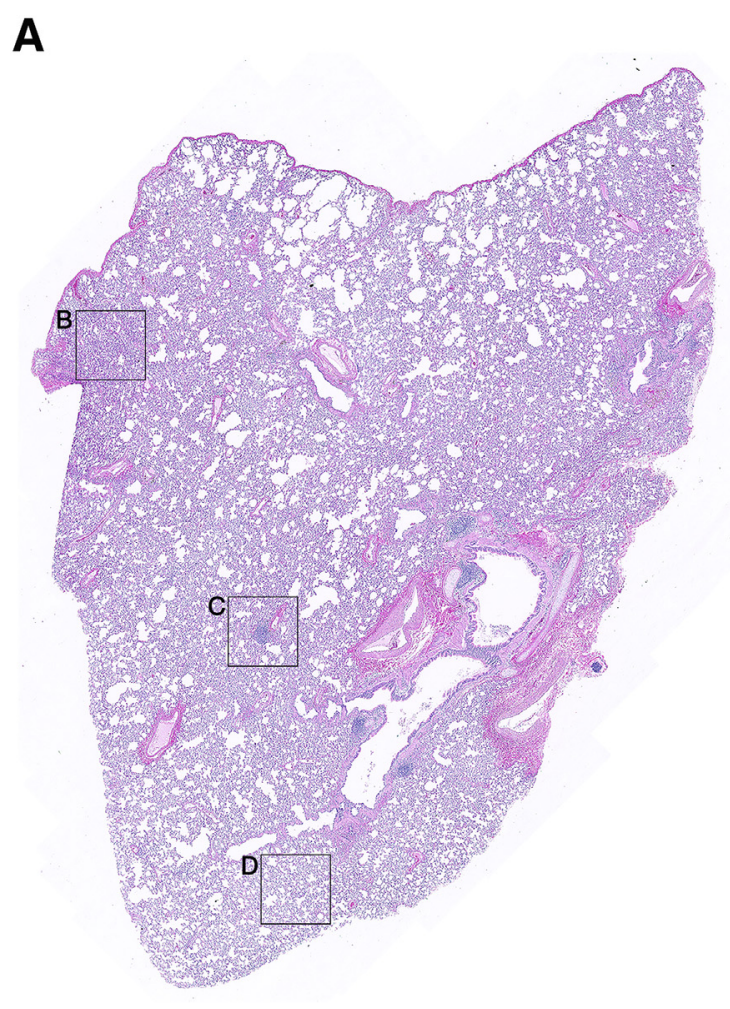

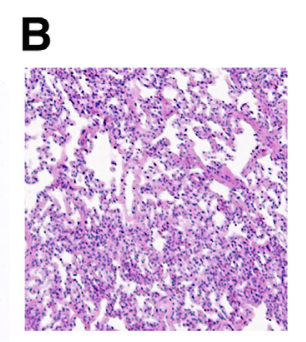
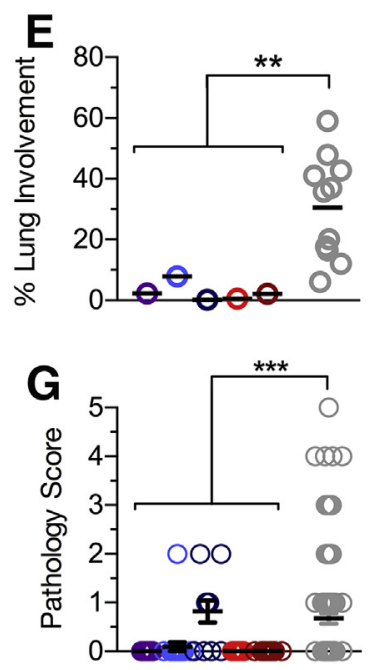

D

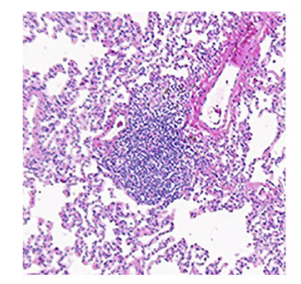

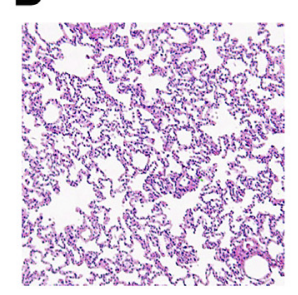

$\mathbf{F}$

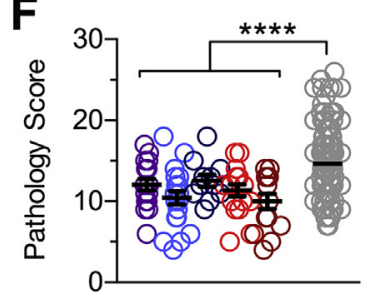

H

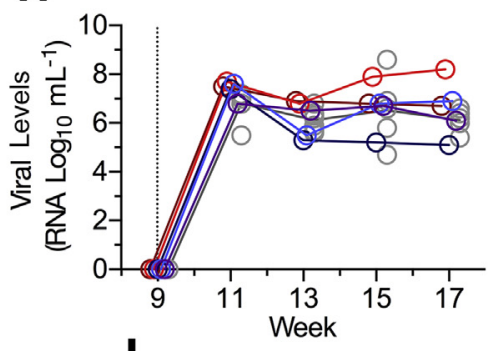

J SIV-Infected T cell

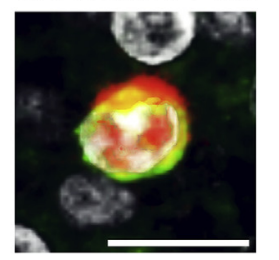

Figure 2 Pulmonary pathology after Mtb $\Delta$ sigH vaccination and simian immunodeficiency virus (SIV) infection. A-D: Hematoxylin and eosin staining of lung sections from a representative animal showing an entire lung section (A), with boxed areas in A shown as enlarged images of consolidation (B), vaccine-induced bronchus-associated lymphoid tissue (BALT) (C), and healthy lung tissue examples (D) corresponding to the boxed regions in A. E: Quantification of overall pathology as percentage of lung involvement. Multiple lung sections per animal were scored and quantitatively compared with those from Mtb/SIV-co-infected animals in total pathology score (F) and lymphangitis (G). H: Peripheral viral loads in vaccinated animals (color) and Mtb/SIV-co-infected animals (gray). Dotted line indicates the time of SIV infection. I: In situ hybridization demonstrating the presence of SIV-infected CD $3^{+}$T cells in the lungs of vaccinated animals. J: Enlarged inset image of an infected cell corresponding to the boxed area in I. Data are expressed as means \pm SEM $(\mathbf{E}-\mathbf{H})$. ${ }^{* *} P<0.01$, ${ }^{* * *} P<0.001$, and $* * * P<0.0001$ using a $t$-test analyzing the mean values of all vaccinated animals versus Mtb/SIV-co-infected animals. Scale bars: $100 \mu \mathrm{m}(\mathbf{I}) ; 5 \mu \mathrm{m}(\mathbf{J})$.

explain the reduced pathology. Mtb/SIV co-infected animals with severe reactivation disease harbored SIV-infected cells in the lung while animals that controlled reactivation were able to minimize viral replication in the lung. These results indicate that viral replication at the site of infection or vaccination can act to inhibit immunity to the persistent bacteria. Permissive viral replication in the lungs of co-infected animals likely increased pathology and decreased immune control of latent TB in $M t b / S I V$ co-infected animals. Upon investigation, it was observed that $M t b \Delta s i g H$-vaccinated animals harbored many SIV-infected $\mathrm{CD}^{+} \mathrm{T}$ cells and a few $\mathrm{CD}^{+} 8^{+} \mathrm{CD} 163^{+}$macrophages (Figure 2, I and J, and Supplemental Figure S2). Hence, in terms of the presence of SIV in the lungs, the $M t b \Delta s i g H$-vaccinated animals resembled $M t b / S I V-c o-i n f e c t e d$ animals that could not control latent infection. However, despite the presence of large numbers of SIV-infected cells in the lungs, the $M t b \Delta s i g H$-vaccinated animals maintained minimal pathology and immune control of the attenuated bacterial vaccine despite productive viral replication in the lungs.

\section{Systemic and Lung Immunity}

We next studied the immune cells responding to both vaccination and SIV infection in both whole blood and in the lung via BAL. Vaccination with Mtb $\Delta \operatorname{sigH}$ resulted in the rapid accumulation of both $\mathrm{CD} 4^{+}$and $\mathrm{CD} 8^{+}$ $\mathrm{T}$ cells in BAL (Figure $3 \mathrm{~A}$ ). We previously demonstrated that $\mathrm{CD} 4^{+} \mathrm{T}_{\mathrm{CM}}$ cells rapidly respond to this vaccination and correlate with strong protection upon lethal challenge. As validation, there was a significant increase in the 
A

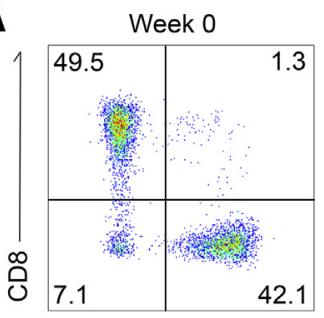

CD4
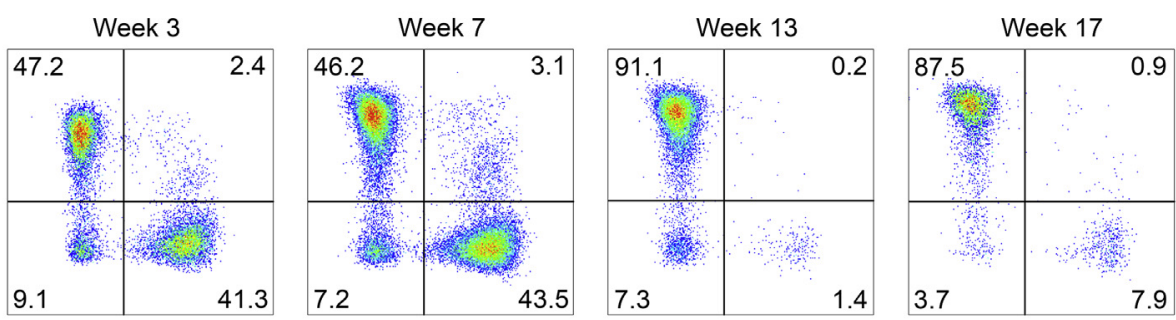

B

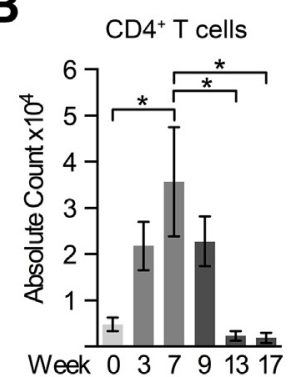

C

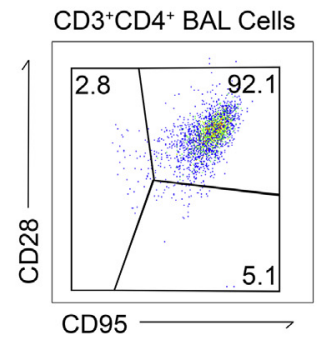

D

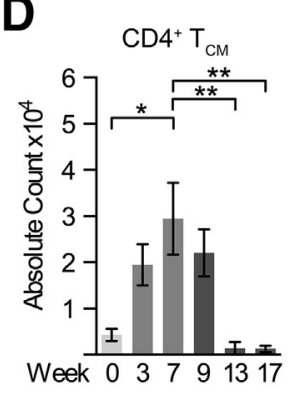

E

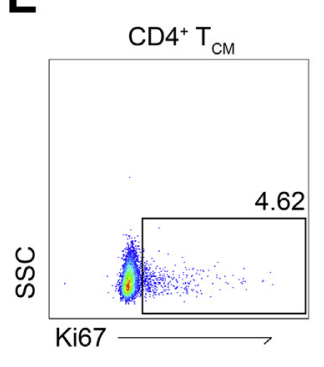

F

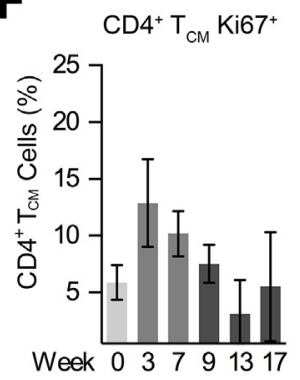

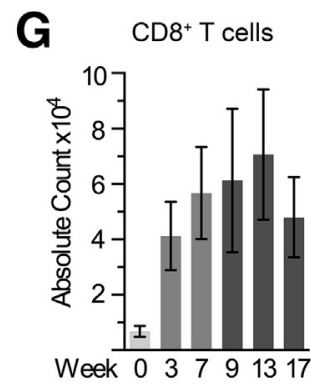
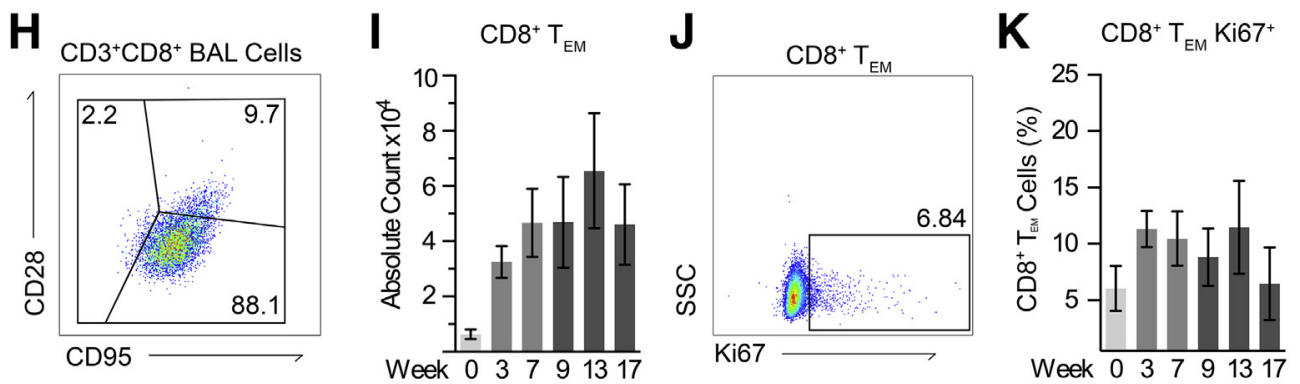

$\mathbf{L}$

\section{M}

N
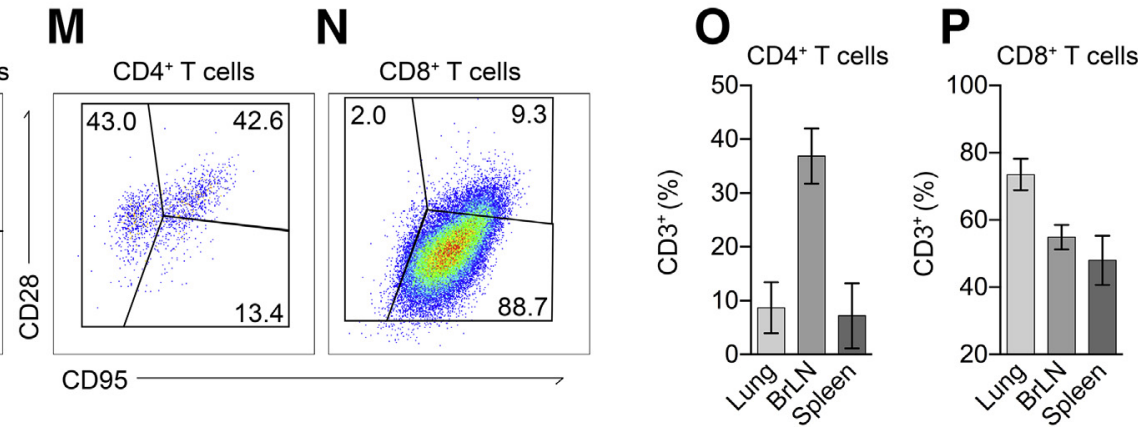

Q $\mathrm{CD}^{4} \mathrm{~T}_{\mathrm{H}} \mathrm{O}$

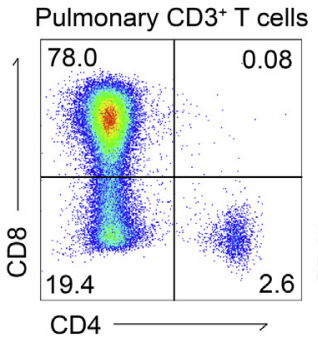

CD95
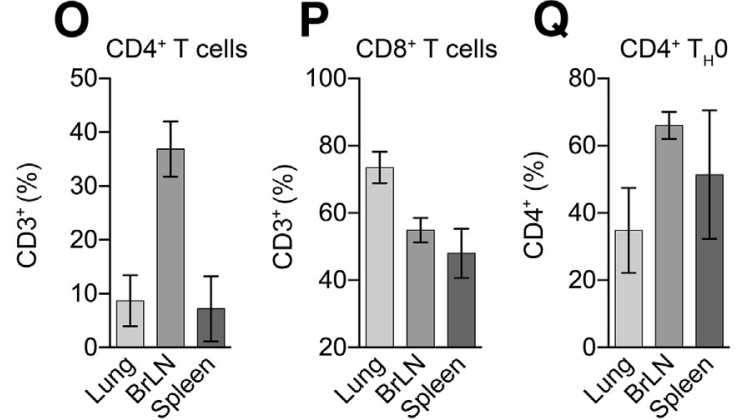

Figure 3 Correlates of cellular immune responses. A: Analysis of $\mathrm{CD}^{+}$lymphocytes found in bronchoalveolar lavage (BAL) throughout the study, demonstrating decline in $\mathrm{CD}^{+} \mathrm{T}$ cells after simian immunodeficiency virus (SIV) infection at week 9. B-D: Absolute number of $\mathrm{CD}^{+}{ }^{+} \mathrm{T}$ cells found in BAL (B), with example flow plot of memory status (C) and absolute count of $\mathrm{CD}^{+}$central memory $\mathrm{T}\left(\mathrm{T}_{\mathrm{CM}}\right)$ cells (D). E and F: Ki67 ${ }^{+}$-proliferating $\mathrm{CD} 4^{+} \mathrm{T}_{\mathrm{CM}}$ cells in BAL. Boxed areas indicate Ki67 ${ }^{+}$cells (E). G-I: $C D 8^{+}$T cells found in BAL, with example flow plot of $C D 8^{+}$T-cell memory status $(\mathbf{H})$ and absolute count of $C D 8^{+}$effector memory $\mathrm{T}\left(\mathrm{T}_{\mathrm{EM}}\right)$ cells (I). J and K: Ki67 ${ }^{+}$-proliferating $\mathrm{CD}^{+} \mathrm{T}_{\mathrm{EM}}$ cells in BAL. Boxed areas indicate Ki67 ${ }^{+}$cells (J). $\mathbf{L}-\mathrm{N}$ : Representative flow plot of pulmonary lymphocytes at the time of euthanasia demonstrating depletion of effector and $\mathrm{CD}^{+} \mathrm{T}_{\mathrm{CM}}$ cells $(\mathrm{M})$ and effector $\mathrm{CD}^{+}{ }^{+}$-cell retention (N). $\mathbf{0}-\mathbf{Q}$ : Percentages of $\mathrm{CD}^{+} \mathrm{T}_{\text {cells }}(\mathbf{0})$ and $\mathrm{CD} 8^{+} \mathrm{T}$ cells $(\mathbf{P})$ in lung, bronchial lymph node $(\mathrm{BrLN})$, and spleen, demonstrating the preservation of naïve (Th0) $\mathrm{CD}^{+}{ }^{+} \mathrm{T}$ cells after SIV infection ( $\left.\mathbf{Q}\right)$. Data are expressed as means \pm SEM (B, D, F, G, I, K, $\mathbf{0}-\mathbf{Q}) .{ }^{*} P<0.05,{ }^{* *} P<0.01$ using one-way analysis of variance with Šídák correction. SSC, side scatter.

number of $\left(\mathrm{CD} 28^{+} \mathrm{CD} 95^{+}\right) \mathrm{CD} 4^{+} \mathrm{T}_{\mathrm{CM}}$ cells responding to vaccination at week 7 and also exhibited rapid proliferation after vaccination as marked by Ki67 positivity (Figure 3, $\mathrm{B}-\mathrm{F})$. However, subsequent SIV infection resulted in the rapid ablation of pulmonary $\mathrm{CD} 4^{+} \mathrm{T}$ cells (Figure $3, \mathrm{~A}$ and B), resulting in a virtually complete loss of $\mathrm{CD}^{+} \mathrm{T}_{\mathrm{CM}}$ cells (Figure 3D). Furthermore, $\mathrm{CD} 8^{+} \mathrm{T}$ cells responding to vaccination persisted after SIV infection and demonstrated proliferation both after vaccination and subsequent infection (Figure 3, G-K). While these differences were apparent in $\mathrm{BAL}$, comparison of $\mathrm{CD}^{+}$and $\mathrm{CD} 8^{+} \mathrm{T}$ cells in whole blood showed no significant differences after either vaccination or SIV infection (Supplemental Figure S3). 
A

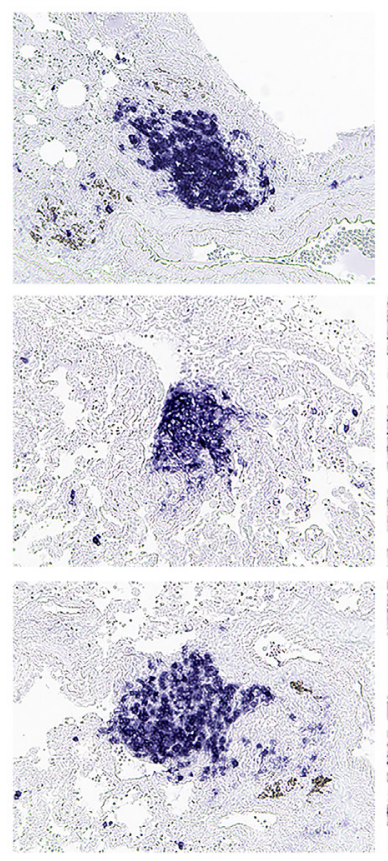

B

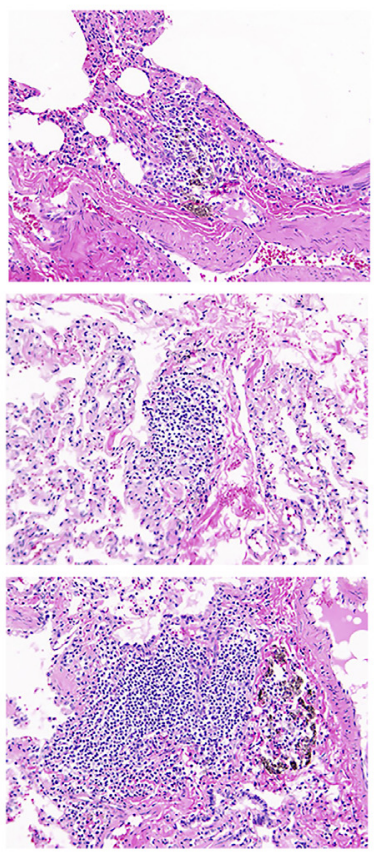

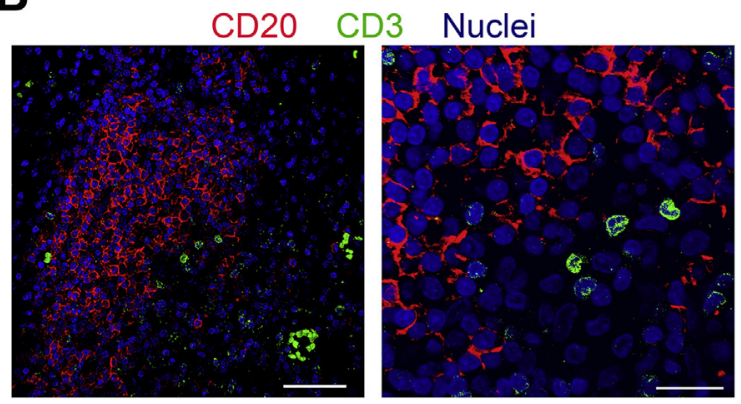

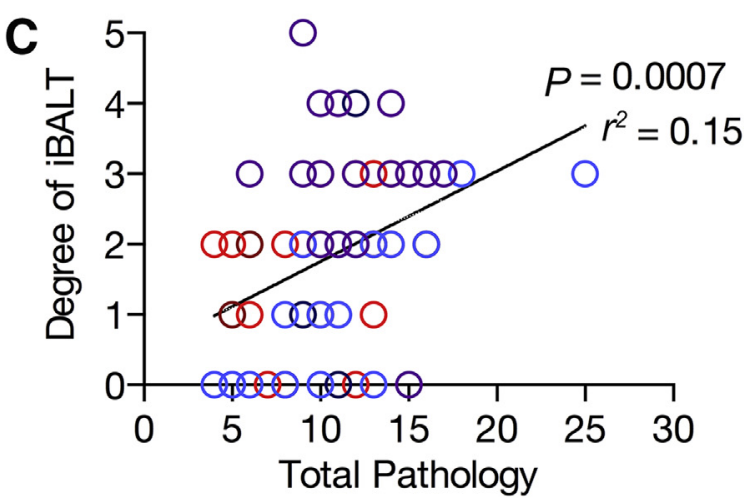

Figure 4 Persistent vaccine-induced bronchus-associated lymphoid tissue (BALT). A: Chromogenic staining with CD20 (left panels) and the respective hematoxylin and eosin staining (right panels) showing B-cell follicles in the lung at euthanasia. B: Immunohistochemistry analysis staining for CD20 B cells, CD3 T cells, and nuclei, showing that T cells remain in BALT. C: Correlation analysis of the degree of BALT formation and the overall pathology score for each lung section analyzed, demonstrating that BALT persists in areas of continued inflammation to maintain immune control of bacterial replication, analyzed using the Pearson $r$ correlation analysis. Data are expressed as correlation values. Scale bars: $100 \mu \mathrm{m}$ (B, right); $25 \mu \mathrm{m}$ (B, left).

We next assessed the level of $\mathrm{CD} 4^{+} \mathrm{T}$-cell depletion in tissues at the time of euthanasia (Figure 3, $\mathrm{L}$ and $\mathrm{N}$ ). The extent of $\mathrm{CD}^{+}{ }^{+}$-cell depletion in lung was comparable to that in BAL; however, relatively greater frequencies of $\mathrm{CD}^{+} \mathrm{T}$ cells persisted in the bronchial lymph nodes (Figure 3, O and P). Examination of the memory status of the few remaining $\mathrm{CD} 4^{+} \mathrm{T}$ cells demonstrated that these cells were primarily $\mathrm{T}_{\mathrm{CM}}$ or naïve (Th0) cells (Figure 3Q). CD4 ${ }^{+}$cells that remained in the bronchial lymph nodes were also predominantly $\mathrm{Th} 0$. The $\mathrm{CD} 8^{+} \mathrm{T}$ cells in lung were primarily $\left(\mathrm{CD} 28^{-} \mathrm{CD} 95^{+}\right)$effector memory $\mathrm{T}$ cells, indicating that $\mathrm{CD}^{+} \mathrm{T}$ cells likely compensate for the absence of $\mathrm{CD}^{+} \mathrm{T}$ cells to facilitate the complete control of this avirulent Mycobacterium (Figure 3P).

\section{Persistence of Bronchus-Associated Lymphoid Tissue}

Presence of BALT strongly correlates with protection in $\Delta s i g H$-vaccinated macaques after lethal challenge ${ }^{5}$ and also correlates with protection from HIV-induced reactivation of latent TB. ${ }^{6}$ BALT is also associated with the natural control of $M t b$ infection in a latent state, ${ }^{4}$ whereas animals developing active disease coincidentally lose granuloma-associated BALT with neutrophilic influx. ${ }^{3}$ We therefore assessed the persistence of vaccine-induced BALT despite the very minimal bacterial burden and ablation of $\mathrm{CD}^{+}{ }^{+} \mathrm{T}$ cells after SIV infection. While only $3.5 \%$ of the analyzed lung sections contained evidence of granulomatous pathology, $84 \%$ of lung sections contained BALT (Figure 4). Chromogenic staining of lung sections with CD20 demonstrated large organized follicles persisted proximal to airways and the pulmonary vasculature (Figure 4). Further assessment of $\mathrm{CD}^{+} \mathrm{T}$ cells demonstrated colocalization of $\mathrm{T}$ cells in these lymphoid follicles (Figure 4). The scored level of BALT persistence strongly correlated with the amount of vaccine- and SIVinduced pathology as assessed by pathologic scores for each lung section (Figure 2F). The present findings support previous work demonstrating that the induction of BALT by $\triangle \operatorname{sig} H$ vaccination correlates with reduced overall pathology. ${ }^{5}$ Furthermore, the ability of BALT to persist for 17 weeks after vaccination, despite SIV infection and a lack of significant antigen stimulation, indicates that mucosal vaccination may drive long-lived tissue-specific immunity.

\section{Discussion}

Development of novel vaccination strategies for TB remains a high priority and significant endeavor. ${ }^{16}$ Correlates of natural immunity are incompletely defined due to the complex nature of $M t b$ infection and the breadth of antigenic responses elicited. ${ }^{36}$ Protection from active disease likely involves various arms of the immune system acting in synergy to control infection. ${ }^{6,37,38}$ This protection is seen in the approximately $90 \%$ of infected individuals able to maintain infection in a latent state. Therefore, a TB vaccine eliciting 
natural immunity through a resolved infection would be ideal. Live attenuated mycobacteria may protect better than either subunit or viral-vector-based candidates due to their broader antigenic repertoires, which can elicit an array of immune responses mimicking natural immunity. Persistence of live attenuated mycobacteria likely drives long-lived memory immune responses through continual bacterial stimulation and an almost complete array of mycobacterial antigens. Mimicking natural infection may drive development of both conventional and unconventional $\mathrm{T}$ cells, natural killer cells and innate lymphocytes, and B-cell responses that include antibody production. The key is to identify mutants unable to invoke pathogen-induced immunomodulatory pathways that hinder the ability of natural immunity to sterilize infection. $M t b$ is constantly exposed to various types of environmental stress during its life cycle and has become dependent on stress-response factors. RNA polymerase $\sigma-\mathrm{H}$ factor $(\mathrm{sigH})$ regulates a key stress-response module and the $\triangle \operatorname{sig} H$ mutant, a poor scavenger of oxidative stress, protects against lethal TB. In this study, we sought to test the safety profile of this leading preclinical, live attenuated vaccine that is deficient in stress response and that demonstrated significant protection upon lethal challenge.

It has been postulated that direct delivery of live attenuated vaccines to the lung can elicit locally protective responses leading to a better control of infection. ${ }^{39-41}$ In addition, this route can permit co-delivery of adjuvants. ${ }^{42}$ Direct delivery of BCG to the pulmonary compartment improves protection against $\mathrm{TB},{ }^{41,43}$ including in the macaque model. ${ }^{44}$ While vaccination with live attenuated mycobacterial vaccines has yielded promising results, the persistence that likely drives protective immune responses also raises safety concerns regarding the extent of attenuation. Despite the vast attenuation of the currently used vaccine, BCG cannot be given to infants with symptomatic HIV due to increased rates of dissemination. Recent data from Sharpe et $\mathrm{al}^{45}$ suggest that direct delivery of BCG to the lung may in fact elicit lesser pathology than the systemic intradermal route, thus alleviating concerns about the safety of mycobacterial vaccine strains delivered directly to the lung. More data are however required before such strains can be considered totally safe in lungs. The issues related to safety and the potential infectivity of the live attenuated $M t b$ strains are only heightened by the choice of the pulmonary, relative to systemic, delivery. Therefore, due to the persistence of the mycobacterial vaccine and the high endemicity of HIV in areas in desperate need of an efficacious TB vaccine, the attenuation of vaccine candidates must be tested in individuals who subsequently become infected with HIV, and they must be proven to be safe.

Using a macaque model of HIV co-infection (using SIV as a surrogate), ${ }^{6,24}$ we first aerosol-vaccinated five nonhuman primates with the live mycobacterial strain $\Delta s i g H$ and successively challenged them with i.v. pathogenic SIV. Animals were monitored throughout the study and euthanized at predetermined end points to determine whether the bacterial vaccine strain persisted or disseminated to extrathoracic organs. Here we demonstrate that vaccinated macaques remain asymptomatic of tuberculous disease throughout the study despite severe depletion of $\mathrm{CD}^{+}{ }^{+} \mathrm{T}_{\mathrm{CM}}$ cells and active replication of SIV in the lung.

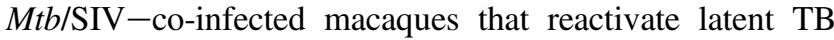
disease were previously shown to have profound $\mathrm{SIV}^{6}$ and TB-associated pathology, ${ }^{8}$ contain SIV-infected cells in pulmonary granulomas, and were characterized by a lack of BALT. If the mutant strain was not attenuated enough, we hypothesized that vaccinated macaques would develop symptoms comparable to Mtb/SIV-co-infected macaques.

However, our results demonstrate that the infection of $\Delta s i g H$-vaccinated macaques with a high dose of pathogenic SIV did not result in TB disease. None of these animals exhibited any clinical, microbiological, or pathologic signs of disease characterized in Mtb/SIV-co-infected macaques. A

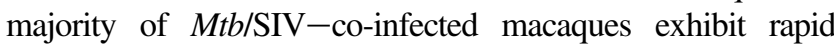
reactivation of latent tuberculosis infection characterized by high bacterial burdens, significant extrapulmonary dissemination, and severe granulomatous pathology. ${ }^{6}$ However, bacilli were barely detectable in the lungs and absent in extrapulmonary tissues of $\Delta s i g H$-vaccinated/SIV-infected macaques. It is important that we report bacterial burden data generated by extensive sampling of the lung compartment, and from every animal individually, and not as a whole group, which would have averaged and masked some of the heterogeneity observed in our experiments. While we could not include a BCG/SIV co-infection experiment in our study design due to some limitations, prior data indicate that BCG infection in rhesus macaques can be reactivated by SIV co-infection. ${ }^{22}$ While the studies were performed at different times/sites and used different (intradermal versus aerosol) routes, it appears that $\triangle \operatorname{sig} H$ may be more attenuated than BCG in rhesus macaques. Another consideration is that rhesus macaques are highly susceptible to mycobacteria, and far more than are Chinese cynomolgus, and yet $\triangle \mathrm{sig} H$ could not be reactivated.

Despite the significant ablation of $\mathrm{CD}^{+} \mathrm{T}$ cells caused by SIV infection, vaccinated macaques were able to maintain control of bacterial replication. As seen in $\mathrm{Mtb} / \mathrm{SIV}-\mathrm{co}-$ infected macaques, both $\mathrm{CD}^{+} \mathrm{T}$ cells and $\mathrm{B}$ cells contribute to improved clinical outcomes. Here we demonstrate that in the absence of effective $\mathrm{CD} 4^{+} \mathrm{T}$-cell responses, $\mathrm{CD} 8^{+} \mathrm{T}$ cells and $\mathrm{B}$ cells are able to persist in the lungs and maintain control of $\Delta s i g H$ replication after SIV infection. The current results reinforce the notion that protective immunity to $M t b$ infection is composed of multiple layers, with $\mathrm{CD} 8^{+}$and $\mathrm{B}$-cell responses playing critical roles in the absence of $\mathrm{CD}^{+}$responses. A key feature of reactivation of latent $M t b$ infection was the presence of SIVinfected cells within pulmonary granulomas, whereas animals that retained control of infection were completely devoid of the virus. Here, we report that substantial quantities of the virus could be detected in the lungs of $\Delta \operatorname{sigH}-$ vaccinated animals and yet the control of mycobacterial infection did not diminish. 
Differential induction of immune responses to $\Delta s i g H$ as compared to wild-type $M t b$ demonstrates that modulation of key aspects of immunity occur in a SigH-dependent manner. BCG may also modulate some aspects of host immunity; however, it lacks the genomic segment RD1, which encompasses highly immunogenic $M t b$ antigens 6-kDa early secreted antigenic target (ESAT-6) and 10-kDa culture filtrate protein (CFP-10), and does not induce long-lived immunity. ${ }^{46}$ Vaccination with BCG and subsequent SIV infection in cynomolgus macaques resulted in a number of animals developing tuberculous disease. ${ }^{22}$ In contrast, our results demonstrate that $\Delta s i g H$ vaccination does not induce tuberculous disease upon acute viral challenge. The virtual absence of disease in immunocompromised macaques highlights that $\Delta s i g H$ may be more attenuated than BCG, yet retains a complete array of $M t b$ antigens and could serve as a better anti-TB vaccine vector. It therefore appears that the inability to sequester thiol-oxidative stress in the absence of the SigH regulon drastically attenuates the Bacillus so that it is rendered nonpathogenic to such an extent that a primary immunodeficiency does not hinder immune control. It remains to be seen whether $\Delta s i g H$-vaccinated/SIV-infected animals will develop TB disease if subsequently infected with $M t b$. This will be a telling experiment, and if protection by $\Delta s i g H$ solely depends on B-cells/iBALT then it is possible that co-infected macaques will still be protected. On the contrary, if high levels of $\mathrm{CD}^{+} \mathrm{T}_{\mathrm{CM}}$ cells and $\mathrm{T}_{\mathrm{CM}}$ /effector memory $\mathrm{CD} 8^{+} \mathrm{T}$ cells recruited to the lungs after $\Delta s i g H$ vaccination play a key role in mediating protection, and if such cells are depleted and unable to proliferate after SIV co-infection, then protection may be compromised.

BCG remains the most widely used vaccine in the world yet is contraindicated in a large population that is in most need of an efficacious TB vaccine. Vaccination with live attenuated mycobacterial vaccines results in superlative protection as compared to subunit or viral vector-based candidates. However, live attenuated vaccines should not be used in HIV-endemic areas until each candidate vaccine can be proven safe in individuals with primary immunodeficiencies. Vaccination with $\Delta s i g H$ resulted in protection comparable to or better than natural immunity, and results from this current study demonstrate that $\Delta s i g H$ is also safe in immunocompromised macaques. Our results suggest that live attenuated mycobacterial vaccines based on the $\Delta s i g H$ vehicle are likely to be both safe and efficacious.

\section{Acknowledgments}

We thank the TNPRC flow cytometry and confocal microscopy core facilities for their assistance.

T.W.F. performed the experiments, analyzed the results, and participated in manuscript preparation; A.V.V. performed the experiments; D.N.L. and P.J.D. analyzed results and performed veterinary pathology; L.A.D.-M. and K.E.R.-L. provided veterinary assistance; A.A.L. performed veterinary pathology and participated in manuscript preparation; K.G.K. and S.A.K. provided funding and analyzed the results; and D.K. and S.M. provided funding, advised on the experimental design, analyzed the results, and participated in manuscript preparation. All of the authors reviewed the manuscript before submission.

\section{Supplementary data}

Supplemental material for this article can be found at https://doi.org/10.1016/j.ajpath.2017.08.014.

\section{References}

1. Tonnis WF, Kersten GF, Frijlink HW, Hinrichs WL, de Boer AH, Amorij JP: Pulmonary vaccine delivery: a realistic approach? J Aerosol Med Pulm Drug Deliv 2012, 25:249-260

2. Sou T, Meeusen EN, de Veer M, Morton DA, Kaminskas LM, McIntosh MP: New developments in dry powder pulmonary vaccine delivery. Trends Biotechnol 2011, 29:191-198

3. Gopal R, Monin L, Torres D, Slight S, Mehra S, McKenna K, Fallert Junecko BA, Reinhart TA, Kolls J, Baez-Saldana R, Cruz-Lagunas A, Rodriguez-Reyna TS, Kumar NP, Tessier P, Roth J, Selman M, BecerrilVillanueva E, Baquera-Heredia J, Cumming B, Kasprowicz VO, Steyn AJ, Babu S, Kaushal D, Zuniga J, Vogl T, Rangel-Moreno J, Khader SA: S100A8/A9 Proteins Mediate Neutrophilic Inflammation and Lung Pathology during Tuberculosis. Am J Respir Crit Care Med 2013, 188:1137-1146

4. Slight SR, Rangel-Moreno J, Gopal R, Lin Y, Fallert Junecko BA, Mehra S, Selman M, Becerril-Villanueva E, Baquera-Heredia J, Pavon L, Kaushal D, Reinhart TA, Randall TD, Khader SA: $\mathrm{CXCR}^{+}{ }^{+}$T helper cells mediate protective immunity against tuberculosis. J Clin Invest 2013, 123:712-726

5. Kaushal D, Foreman TW, Gautam US, Alvarez X, Adekambi T, RangelMoreno J, Golden NA, Johnson AM, Phillips BL, Ahsan MH, RussellLodrigue KE, Doyle LA, Roy CJ, Didier PJ, Blanchard JL, Rengarajan J, Lackner AA, Khader SA, Mehra S: Mucosal vaccination with attenuated Mycobacterium tuberculosis induces strong central memory responses and protects against tuberculosis. Nat Commun 2015, 6:8533

6. Foreman TW, Mehra S, LoBato DN, Malek A, Alvarez X, Golden NA, Bucsan AN, Didier PJ, Doyle-Meyers LA, Russell-Lodrigue KE, Roy CJ, Blanchard J, Kuroda MJ, Lackner AA, Chan J, Khader SA, Jacobs WR Jr, Kaushal D: CD4+ T-cell-independent mechanisms suppress reactivation of latent tuberculosis in a macaque model of HIV coinfection. Proc Natl Acad Sci U S A 2016, 113:E5636-E5644

7. Kaushal D, Mehra S: Faithful Experimental Models of Human Infection. Mycobact Dis 2012, 2:e108

8. Kaushal D, Mehra S, Didier PJ, Lackner AA: The non-human primate model of tuberculosis. J Med Primatol 2012, 41:191-201

9. Ottenhoff TH, Kaufmann SH: Vaccines against tuberculosis: where are we and where do we need to go? PLoS Pathog 2012, 8:e1002607

10. Sampson SL, Mansfield KG, Carville A, Magee DM, Quitugua T, Howerth EW, Bloom BR, Hondalus MK: Extended safety and efficacy studies of a live attenuated double leucine and pantothenate auxotroph of Mycobacterium tuberculosis as a vaccine candidate. Vaccine 2011, 29:4839-4847

11. Sampson SL, Dascher CC, Sambandamurthy VK, Russell RG, Jacobs WR Jr, Bloom BR, Hondalus MK: Protection elicited by a double leucine and pantothenate auxotroph of Mycobacterium tuberculosis in guinea pigs. Infect Immun 2004, 72:3031-3037

12. Larsen MH, Biermann K, Chen B, Hsu T, Sambandamurthy VK, Lackner AA, Aye PP, Didier P, Huang D, Shao L, Wei H, Letvin NL, Frothingham R, Haynes BF, Chen ZW, Jacobs WR Jr: Efficacy and safety of live attenuated persistent and rapidly cleared Mycobacterium tuberculosis vaccine candidates in non-human primates. Vaccine 2009, 27:4709-4717

13. Sambandamurthy VK, Derrick SC, Hsu T, Chen B, Larsen MH, Jalapathy KV, Chen M, Kim J, Porcelli SA, Chan J, Morris SL, 
Jacobs WR Jr: Mycobacterium tuberculosis DeltaRD1 DeltapanCD: a safe and limited replicating mutant strain that protects immunocompetent and immunocompromised mice against experimental tuberculosis. Vaccine 2006, 24:6309-6320

14. Sambandamurthy VK, Wang X, Chen B, Russell RG, Derrick S, Collins FM, Morris SL, Jacobs WR Jr: A pantothenate auxotroph of Mycobacterium tuberculosis is highly attenuated and protects mice against tuberculosis. Nat Med 2002, 8:1171-1174

15. Eibl MM, Wolf HM: Vaccination in patients with primary immune deficiency, secondary immune deficiency and autoimmunity with immune regulatory abnormalities. Immunotherapy 2015, 7:1273-1292

16. McShane H, Jacobs WR, Fine PE, Reed SG, McMurray DN, Behr M, Williams A, Orme IM: BCG: myths, realities, and the need for alternative vaccine strategies. Tuberculosis (Edinb) 2012, 92:283-288

17. Hesseling AC, Cotton MF, Marais BJ, Gie RP, Schaaf HS, Beyers N, Fine PE, Abrams EJ, Godfrey-Faussett P, Kuhn L: BCG and HIV reconsidered: moving the research agenda forward. Vaccine 2007, 25:6565-6568

18. Hesseling AC, Marais BJ, Gie RP, Schaaf HS, Fine PE, GodfreyFaussett P, Beyers N: The risk of disseminated Bacille Calmette-Guerin (BCG) disease in HIV-infected children. Vaccine 2007, 25:14-18

19. Hesseling AC, Rabie H, Marais BJ, Manders M, Lips M, Schaaf HS, Gie RP, Cotton MF, van Helden PD, Warren RM, Beyers N: Bacille Calmette-Guerin vaccine-induced disease in HIV-infected and HIVuninfected children. Clin Infect Dis 2006, 42:548-558

20. Spertini F, Audran R, Chakour R, Karoui O, Steiner-Monard V, Thierry AC, Mayor CE, Rettby N, Jaton K, Vallotton L, LazorBlanchet C, Doce J, Puentes E, Marinova D, Aguilo N, Martin C: Safety of human immunisation with a live-attenuated Mycobacterium tuberculosis vaccine: a randomised, double-blind, controlled phase I trial. Lancet Respir Med 2015, 3:953-962

21. Mehra S, Golden NA, Stuckey K, Didier PJ, Doyle LA, RussellLodrigue KE, Sugimoto C, Hasegawa A, Sivasubramani SK, Roy CJ, Alvarez X, Kuroda MJ, Blanchard JL, Lackner AA, Kaushal D: The Mycobacterium tuberculosis stress response factor SigH is required for bacterial burden as well as immunopathology in primate lungs. J Infect Dis 2012, 205:1203-1213

22. Chen ZW, Zhou D, Chalifoux L, Lee-Parritz D, Mansfield K, Lord CI, Letvin NL: Disseminated granulomatous disease in a simian immunodeficiency virus- and bacille Calmette-Guerin-infected rhesus monkey. AIDS 1997, 11:266-267

23. Mehra S, Pahar B, Dutta NK, Conerly CN, Philippi-Falkenstein K, Alvarez X, Kaushal D: Transcriptional reprogramming in nonhuman primate (rhesus macaque) tuberculosis granulomas. PLoS One 2010, 5:e12266

24. Mehra S, Golden NA, Dutta NK, Midkiff CC, Alvarez X, Doyle LA, Asher M, Russell-Lodrigue K, Monjure C, Roy CJ, Blanchard JL, Didier PJ, Veazey RS, Lackner AA, Kaushal D: Reactivation of latent tuberculosis in rhesus macaques by coinfection with simian immunodeficiency virus. J Med Primatol 2011, 40:233-243

25. Mehra S, Foreman TW, Didier PJ, Ahsan MH, Hudock TA, Kissee R, Golden NA, Gautam US, Johnson AM, Alvarez X, RussellLodrigue KE, Doyle LA, Roy CJ, Niu T, Blanchard JL, Khader SA, Lackner AA, Sherman DR, Kaushal D: The DosR regulon modulates adaptive immunity and is essential for M. tuberculosis persistence. Am J Respir Crit Care Med 2015, 191:1185-1196

26. Dutta NK, Mehra S, Didier PJ, Roy CJ, Doyle LA, Alvarez X, Ratterree M, Be NA, Lamichhane G, Jain SK, Lacey MR, Lackner AA, Kaushal D: Genetic requirements for the survival of tubercle bacilli in primates. J Infect Dis 2010, 201:1743-1752

27. Phillips BL, Mehra S, Ahsan MH, Selman M, Khader SA, Kaushal D: LAG3 expression in active Mycobacterium tuberculosis infections. Am J Pathol 2015, 185:820-833

28. Mothe BR, Lindestam Arlehamn CS, Dow C, Dillon MB, Wiseman RW, Bohn P, Karl J, Golden NA, Gilpin T, Foreman TW, Rodgers MA, Mehra S, Scriba TJ, Flynn JL, Kaushal D, O'Connor DH, Sette A: The TB-specific CD4 T cell immune repertoire in both cynomolgus and rhesus macaques largely overlap with humans. Tuberculosis (Edinb) 2015, 95:722-735
29. Levine DM, Dutta NK, Eckels J, Scanga C, Stein C, Mehra S, Kaushal D, Karakousis PC, Salamon H: A tuberculosis ontology for host systems biology. Tuberculosis (Edinb) 2015, 95:570-574

30. Kaushal D, Schroeder BG, Tyagi S, Yoshimatsu T, Scott C, Ko C, Carpenter L, Mehrotra J, Manabe YC, Fleischmann RD, Bishai WR: Reduced immunopathology and mortality despite tissue persistence in a Mycobacterium tuberculosis mutant lacking alternative sigma factor, SigH. Proc Natl Acad Sci U S A 2002, 99:8330-8335

31. Mehra S, Kaushal D: Functional genomics reveals extended roles of the Mycobacterium tuberculosis stress response factor sigmaH. J Bacteriol 2009, 191:3965-3980

32. Committee for the Update of the Guide for the Care and Use of Laboratory Animals; National Research Council: Guide for the Care and Use of Laboratory Animals: Eighth Edition. Washington, DC, National Academies Press, 2011

33. Darrah PA, Bolton DL, Lackner AA, Kaushal D, Aye PP, Mehra S, Blanchard JL, Didier PJ, Roy CJ, Rao SS, Hokey DA, Scanga CA, Sizemore DR, Sadoff JC, Roederer M, Seder RA: Aerosol vaccination with AERAS-402 elicits robust cellular immune responses in the lungs of rhesus macaques but fails to protect against high-dose Mycobacterium tuberculosis challenge. J Immunol 2014, 193:1799-1811

34. Mehra S, Alvarez X, Didier PJ, Doyle LA, Blanchard JL, Lackner AA, Kaushal D: Granuloma correlates of protection against tuberculosis and mechanisms of immune modulation by Mycobacterium tuberculosis. J Infect Dis 2013, 207:1115-1127

35. Li Q, Skinner PJ, Duan L, Haase AT: A technique to simultaneously visualize virus-specific CD8+ T cells and virus-infected cells in situ. J Vis Exp 2009, 2009(30):e1561

36. Fletcher HA: Correlates of immune protection from tuberculosis. Curr Molecular Medicine 2007, 7:319-325

37. Woodworth JS, Behar SM: Mycobacterium tuberculosis-specific CD8+ T cells and their role in immunity. Crit Rev Immunol 2006, 26:317-352

38. Lu LL, Chung AW, Rosebrock TR, Ghebremichael M, Yu WH, Grace PS, Schoen MK, Tafesse F, Martin C, Leung V, Mahan AE, Sips M, Kumar MP, Tedesco J, Robinson H, Tkachenko E, Draghi M, Freedberg KJ, Streeck H, Suscovich TJ, Lauffenburger DA, Restrepo BI, Day C, Fortune SM, Alter G: A functional role for antibodies in tuberculosis. Cell 2016, 167:433-443.e14

39. Lu D, Hickey AJ: Pulmonary vaccine delivery. Expert Rev Vaccines 2007, 6:213-226

40. Fiegel J, Garcia-Contreras L, Thomas M, VerBerkmoes J, Elbert K, Hickey A, Edwards D: Preparation and in vivo evaluation of a dry powder for inhalation of capreomycin. Pharm Res 2008, 25:805-811

41. Garcia-Contreras L, Wong YL, Muttil P, Padilla D, Sadoff J, Derousse J, Germishuizen WA, Goonesekera S, Elbert K, Bloom BR, Miller R, Fourie PB, Hickey A, Edwards D: Immunization by a bacterial aerosol. Proc Natl Acad Sci U S A 2008, 105:4656-4660

42. Manjaly Thomas ZR, McShane H: Aerosol immunisation for TB: matching route of vaccination to route of infection. Trans R Soc Trop Med Hyg 2015, 109:175-181

43. Derrick SC, Kolibab K, Yang A, Morris SL: Intranasal administration of Mycobacterium bovis BCG induces superior protection against aerosol infection with Mycobacterium tuberculosis in mice. Clin Vaccine Immunol 2014, 21:1443-1451

44. Barclay WR, Busey WM, Dalgard DW, Good RC, Janicki BW, Kasik JE, Ribi E, Ulrich CE, Wolinsky E: Protection of monkeys against airborne tuberculosis by aerosol vaccination with bacillus Calmette-Guerin. Am Rev Respir Dis 1973, 107:351-358

45. Sharpe S, White A, Sarfas C, Sibley L, Gleeson F, McIntyre A, Basaraba R, Clark S, Hall G, Rayner E, Williams A, Marsh PD, Dennis M: Alternative BCG delivery strategies improve protection against Mycobacterium tuberculosis in non-human primates: protection associated with mycobacterial antigen-specific CD4 effector memory T-cell populations. Tuberculosis (Edinb) 2016, 101:174-190

46. Andersen P, Doherty TM: The success and failure of BCG implications for a novel tuberculosis vaccine. Nat Rev Microbiol 2005 3:656-662 